\title{
Differences in metabolic response to Loma salmonae infection in juvenile rainbow trout Oncorhynchus mykiss and brook trout Salvelinus fontinalis
}

\author{
Mark D. Powell ${ }^{1, *}$, David J. Speare ${ }^{2}$, Joanne Daley ${ }^{2}$, Jan Lovy ${ }^{2}$ \\ ${ }^{1}$ School of Aquaculture, Tasmanian Aquaculture and Fisheries Institute, University of Tasmania, Locked Bag 1370, \\ Launceston, Tasmania 7250, Australia \\ ${ }^{2}$ Department of Pathology and Microbiology, Atlantic Veterinary College, University of Prince Edward Island, \\ 550 University Avenue, Charlottetown, Prince Edward Island C1A 4P3, Canada
}

\begin{abstract}
Routine and post-exercise metabolic rates were measured for juvenile rainbow trout Oncorhynchus mykiss and brook trout Salvelinus fontinalis infected with the microsporidium gill parasite Loma salmonae under laboratory conditions. Rainbow trout increased routine and postexercise metabolic rate in response to infection compared with controls. Brook trout, on the other hand, lowered routine metabolic rate without effecting post-exercise metabolic rate compared to controls. The result of these 2 different strategies may either reflect defense of metabolic scope or a difference in the rate of recovery of the excess post-exercise oxygen consumption between the 2 species in response to the same infection.
\end{abstract}

KEY WORDS: Loma salmonae $\cdot$ Metabolic rate $\cdot$ Microsporidian · Oxygen consumption · Salmonid

\section{INTRODUCTION}

Microsporidian gill disease caused by Loma salmonae is of major economic significance to salmonid husbandry in hatcheries (Hauck 1984) and marine netpens (Kent et al. 1989, Speare et al. 1989), where it forms xenomas of hypertrophied cells visible as white cysts on the gills. On the basis of PCR-based detection, it is suggested that in rainbow trout at $15^{\circ} \mathrm{C}$ the parasite enters the host through the gut, quickly migrates to cardiovascular tissues, and then migrates to the gills where characteristic xenomas are formed (Speare et al. 1998, Sanchez et al. 2000, 2001a,b). Of particular interest is that the growth rate of the fish is suppressed almost at the onset of xenoma resolution, when xenomas are replaced by a multifocal branchitis (Speare et al. 1998).

Although metabolic rates have been measured for most salmonid species, little information exists with regard to the effects of disease on this parameter. Fisk et al. (2002) noted that in Atlantic salmon Salmo salar L. there was no difference in routine metabolic rates between fish affected by amoebic gill disease and control fish. However, under hypoxia, infected individuals had higher oxygen consumption rates, indicating a possible increase in metabolic scope. The aim of the present study was to examine routine and maximal metabolic rate in Loma salmonae-infected freshwater rainbow and brook trout.

\section{MATERIALS AND METHODS}

Juvenile rainbow trout Oncorhynchus mykiss (mean wt $34.4 \pm 1.7 \mathrm{~g} \mathrm{SE}$, mean fork length $15.4 \pm 0.2 \mathrm{~cm} \mathrm{SE})$ and brook trout Salvelinus fontinalis (mean wt $33.4 \pm$ $2.4 \mathrm{~g} \mathrm{SE}$, mean fork length $15.2 \pm 0.3 \mathrm{~cm} \mathrm{SE}$ ) were obtained from Cardigan Fish hatchery, Cardigan, 
Prince Edward Island, and acclimated at $15^{\circ} \mathrm{C}$ for several months in the aquarium facility of the Atlantic Veterinary College, in Charlottetown.

A total of 150 fishes were distributed between 3 flow-through tanks, and individuals in 2 of the tanks were infected with $2 \times 10^{6}$ Loma salmonae spores by feeding with infected gill tissue. The third tank contained uninfected fishes (control). The L. salmonae spores fed to the fishes had been isolated previously from infected rainbow trout or brook trout. The brook trout Salvelinus-variant of L. salmonae was derived from that described by Sanchez et al. (2001b), whereby the sequential pathology is the same as that for the Oncorhynchus-variant used in rainbow trout. This standard method of infection challenge with $L$. salmonae results in $100 \%$ of the fishes becoming infected within $6 \mathrm{wk}$ (Speare et al. 1998). Water in all tanks was maintained at $15^{\circ} \mathrm{C}$ and $95 \%$ air-saturation. The fishes were fed daily (equivalent of $2 \%$ of their body weight) on a commercial extruded-pellet diet (HiPro 3.0 GR, Corey Feed Mills).

After 4 wk post-inoculation, the fishes were starved for $24 \mathrm{~h}$ prior to being randomly selected and placed for $24 \mathrm{~h}$ into individual, black, acrylic respirometer chambers (internal volume approximately 1 l) supplied with the same flow-through freshwater as that supplying the tanks. Food was withheld from fish whilst they were in the respirometer chambers. A total of 9 rainbow trout and 8 brook trout were tested from each treatment (infected or uninfected controls). Control and infected individuals of each species were tested on the same day.

To determine oxygen uptake, the water flow to each chamber was stopped and the chamber sealed. A $1 \mathrm{ml}$ water sample was removed and injected into a thermostatically controlled oxygen electrode (1302 electrode, Strathkelvin instruments) calibrated against a $2 \%$ $\mathrm{NaSO}_{3}$ solution (zero) and air-saturated freshwater ( $158 \mathrm{mmHg})$. The electrode was connected to a Strathkelvin Instruments model $782 \mathrm{O}_{2}$ meter. A second water sample was removed after $15 \mathrm{~min}$ and remeasured, after which the water flow was restored to the respirometer chambers. Oxygen consumption rate, $\mathrm{MO}_{2}$, was calculated as below:

$$
\frac{\left[\left(\mathrm{PO}_{2 \mathrm{i}}-\mathrm{PO}_{2 \mathrm{e}}\right) \times \alpha\right] \times V}{t \times M}
$$

modified from Cech (1990)

where $\mathrm{PO}_{2 \mathrm{i}}$ and $\mathrm{PO}_{2 \mathrm{e}}$ are the initial and final water oxygen tensions respectively ( $\mathrm{mm} \mathrm{Hg}), \alpha$ is the molar oxygen solubility in water (after Cameron 1986) in mmol $\mathrm{O}_{2} \mathrm{l}^{-1} \mathrm{~mm} \mathrm{Hg}^{-1}, V$ is the respirometer chamber volume (1), $t$ is the measurement time (15 min) and $M$ is the mass of the fish (g). Removal of the water sample enables a small amount of air to enter the chamber. However, at water oxygen tensions used in this study (Table 1), oxygen transfer is negligible (M. D. Powell unpubl.) and within the margin of error acceptable for measurements using static respirometry. However, all measurements were corrected for the oxygen transfer rate from the air to the water.

The same fishes were then individually removed from their respective respirometer chambers and 'chased' (i.e. forced into continual swimming) according to the method of Altimiras et al. (2002). Briefly, each fish was placed in a 101 bucket of water $\left(15^{\circ} \mathrm{C}\right)$ to which oxygen was added to maintain $120 \%$ air saturation (measured by YSI 550 dissolved oxygen meter: Yellow Springs Instruments), and was then chased in the bucket using a blunt stick or by hand to ensure that it swam continuously for $10 \mathrm{~min}$. The fish was then immediately returned to the respirometer chamber (transfer time $<15 \mathrm{~s}$ ), which was sealed; oxygen measurements were then made as described above. All fishes were subsequently removed from the respirometers. Rainbow trout were euthanased with an overdose of benzocaine ( $>60 \mathrm{mg} \mathrm{l}^{-1}$ ), their gills removed, and Loma salmonae xenomas on the first gill arch were counted using a dissecting microscope. The remaining gill arches were fixed in 10\% neutral buffered formalin and processed for histological examination. Brook trout were anaesthetised with benzocaine $\left(60 \mathrm{mg} \mathrm{l}^{-1}\right)$ and non-lethally screened, and their gills scored for xenomas infection as clear (0), light (1), medium (2) or heavy (3) under a dissecting microscope (similar to the method of Ramsay et al. 2003). We killed 3 L. salmonae-infected brook trout with an overdose of benzocaine anaesthetic, and their gills were dissected and fixed in $10 \%$ neutral buffered formalin and processed for histological examination.

Routine (non-chased) and post-exercise (chased) oxygen consumption rates were compared for each 
species using a 2-factor repeated-measures analysis of variance with control/infected and routine/post-exercise measurement as fixed factors. Where differences were detected, Bonferroni post-hoc comparisons were used to identify differences in means; $p$ values $<0.05$ were considered statistically significant.

\section{RESULTS AND DISCUSSION}

After $4 \mathrm{wk}$ post-inoculation, rainbow trout contained $1.8 \pm 0.8$ (mean $\pm \mathrm{SE}$ ) xenomas per arch compared to zero in the controls. Although this level of infection is low compared with that reported for other studies (Becker et al. 2002), 4 wk post-infection represented a point at which the infection was increasing rapidly. Some rainbow trout were also tested at Week 7 postinfection with identical results (M. D. Powell unpubl.). Similarly infected brook trout scored an average of 2.0 ( \pm 0.4 SE) compared with controls that had no xenomas. There were no differences in the presentation of xenomas on the gills of rainbow trout or brook trout (Fig. 1).

For both species tested, routine oxygen consumption rates of controls were equivalent to those measured in brown trout at similar temperatures by Altimiras et al. (2002). In our study, post-exercise oxygen consumption rates were higher than those for pre-exercise (routine) (rainbow trout: $F_{8,35} 114.9, \mathrm{p}<0.0001$; brook trout: $F_{7,31}$ 88.2, $\mathrm{p}<0.0001$ ) (Fig. 2). Both the pre-exercise (routine) and post-exercise oxygen consumption of rainbow trout was higher in Loma salmonae-infected fishes compared with uninfected controls $\left(F_{8,35} 69.18\right.$, $\mathrm{p}<0.0001)$. However, in brook trout the pre-exercise

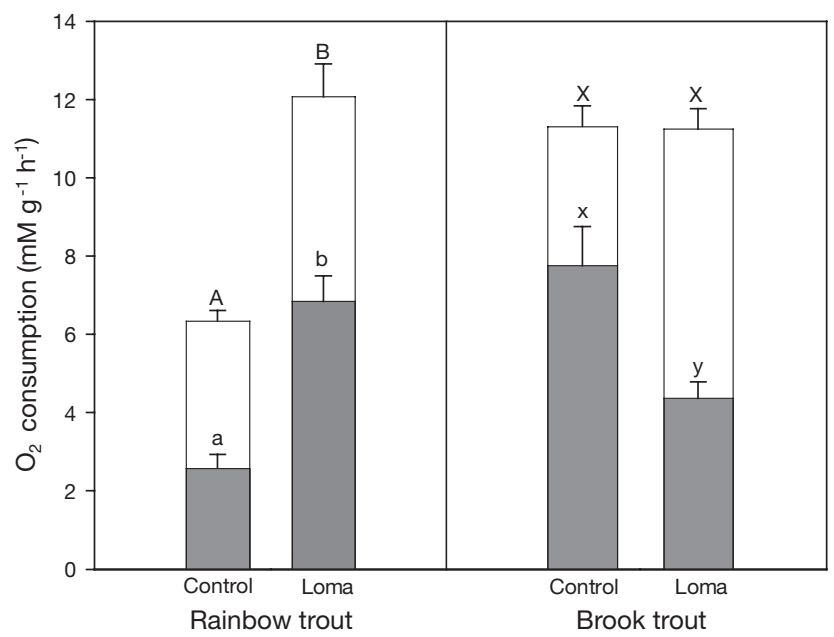

Fig. 2. Oncorhynchus mykiss and Salvelinus fontinalis. Mean $(+\mathrm{SE})$ routine and maximal oxygen consumption rates for control and 4 wk Loma salmonae-infected (Loma) rainbow trout $(\mathrm{n}=9)$ and brook trout $(\mathrm{n}=8)$. Different letters indicate significant differences between routine (shaded) and maximal (open) rates at $p>0.05$

(routine) oxygen consumption rate of L. salmonaeinfected fish was lower than that of controls, and postexercise oxygen consumption rates were similar between control and L. salmonae-infected fish $\left(F_{7,31}\right.$ 5.63, p = 0.0494) (Fig. 2).

The routine and post-exercise oxygen consumption rates of rainbow trout were regressed against xenoma number to determine whether the level of infection influenced the rate of oxygen consumption. A weak, albeit non-significant, relationship was found for both oxygen consumption rates (Fig. 3). It was not possible

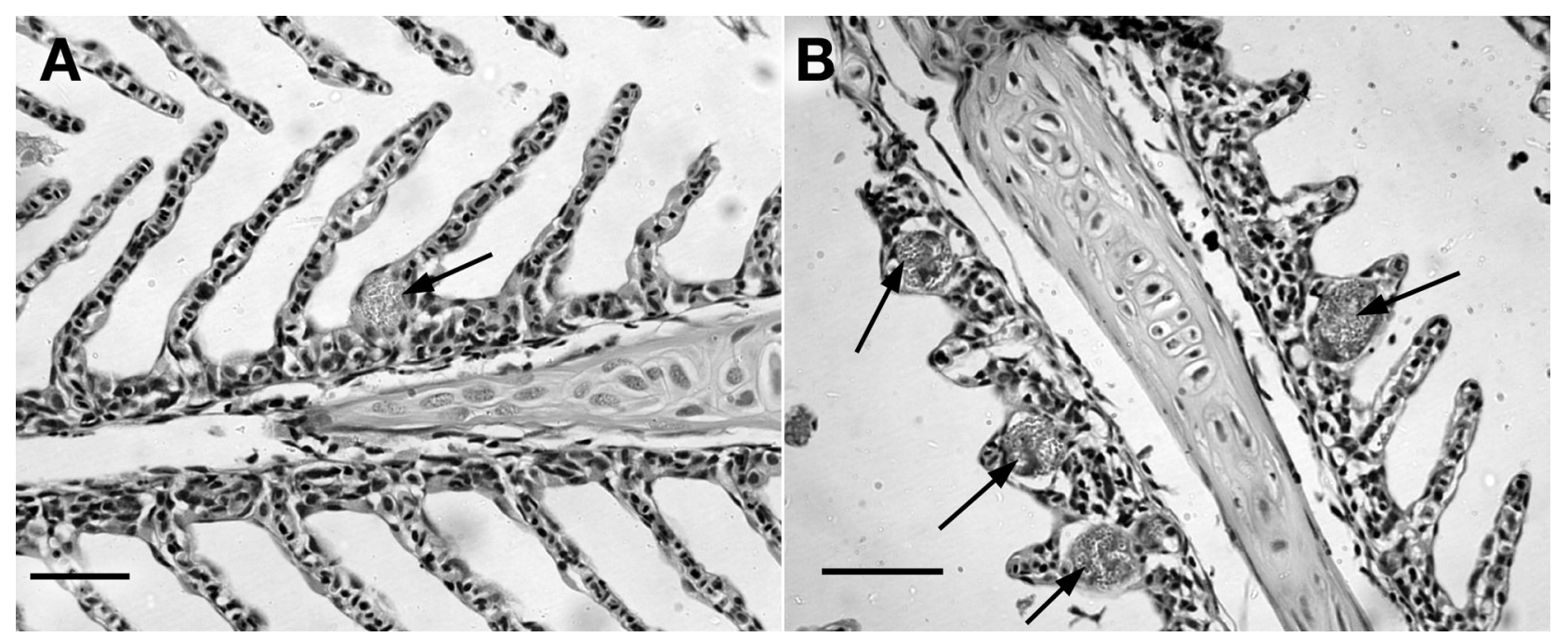

Fig. 1. (A) Oncorhynchus mykiss; (B) Salvelinus fontinalis. Gill xenomas (arrowed) after 4 wk infection with Loma salmonae. $($ H\&E Stain; scale bars $=50 \mu \mathrm{m})$ 


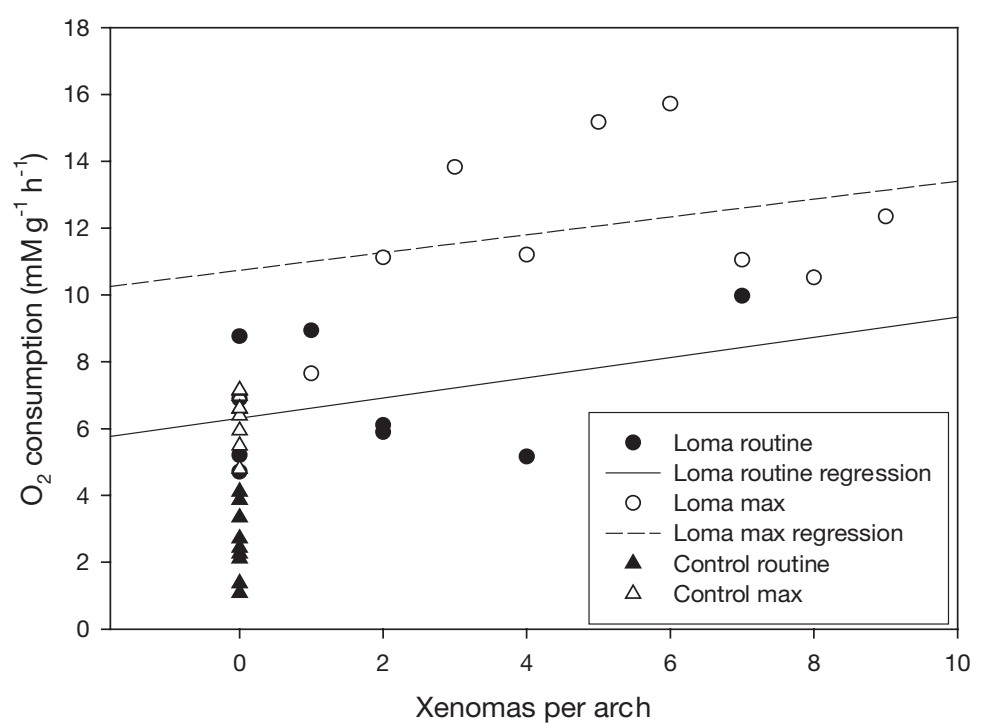

Fig. 3. Oncorhynchus mykiss. Scatter-plot of oxygen consumption rate versus number of xenomas per gill arch for control and Loma salmonaeinfected fish (Loma). Regression lines represent routine (continuous line: slope $=0.397, r^{2}=0.142$ ) and post-exercise (dashed line: slope $=0.303$, $r^{2}=0.143$ ) oxygen consumption rates for L. salmonae-infected fish portional to $\mathrm{MO}_{2 \max }$ and we assume that $\mathrm{MO}_{2 \text { routine }}$ is a proxy for standard metabolic rate $\mathrm{MO}_{2 \text { standard }}$ (an instantaneous rate of the lowest measured oxygen consumption within a $24 \mathrm{~h}$ period, and not possible to determine in this study), then it may indicate that the metabolic scope (i.e. the difference between standard and maximal metabolic rate [Cech 1990]) is defended in L. salmonae-infected trout even though the $\mathrm{MO}_{2 \text { routine }}$ is elevated (Fig. 2). Moreover, the level of infection had no effect on the difference between routine and post-exercise oxygen consumption rates (Fig. 3). Brook trout, on the other hand, appear to use a different metabolic strategy. Routine oxygen consumption decreased in fish with L. salmonae infection, and postexercise (maximum) oxygen consumption remained the same as that of controls. This suggested that either the metabolic cope was effectively increased or else the EPOC was greater than in controls. Either way, the response to a similar infection differed between the 2 species.

This indicates that the maximal oxygen requirements of the 2 species may differ, depending upon whether they are infected or not, and upon the level of stress (exercise) to which they are subjected.

ferences in the oxygen consumption rate re (metabolic rate) of rainbow trout and brook trout to Loma salmonae infection. In rainbow trout, routine metabolic rate was increased in infected fish compared with controls (Fig. 2), whereas in brook trout there was a decrease in routine metabolic rate. Although maximal metabolic rates (post-exercise) were significantly higher than routine rates for both species, in rainbow trout the maximal rate for infected fish was higher than that for controls of the same species. In fact, the maximal rate for control fish was the same as the routine rate for the infected group. However, in brook trout, the maximal metabolic rates were identical for both control and infected fish.

Following exercise, oxygen consumption rate is at its maximal value $\left(\mathrm{MO}_{2 \max }\right)$; however, this is in effect an instantaneous rate, with the recovery from exercise resulting in excessive post-exercise oxygen consumption (EPOC) (Lee et al. 2003). In our study it was not possible to distinguish between the EPOC and $\mathrm{MO}_{2 \max }$. However, Lee (2002, cited in Lee et al. 2003) claimed that both the EPOC and the rate of recovery from exercise are proportional to $\mathrm{MO}_{2 \max }$. From our results it would therefore appear that rainbow trout infected with Loma salmonae recover from exercise at a similar rate as uninfected fish (assuming that the difference between routine and post-exercise oxygen consumption rates equates with EPOC). If the EPOC is pro-
Acknowledgements. Thanks to Dr. R. Butler for his comments reviewers for their comments. This work was supported in part by an NSERC strategic grant to D.J.S. and an ARC Large grant to M.D.P.

\section{LITERATURE CITED}

Altimiras J, Axelsson M, Claireaux G, Lefrancois C, Mercier C, Farrell AP (2002) Cardiorespiratory status of triploid brown trout during swimming at two acclimation temperatures. J Fish Biol 60:102-116 ensin dose and treatment time on xenoma reduction in microsporidial gill disease in rainbow trout Oncorhynchus mykiss (Walbaum). J Fish Dis 25:673-680

Cameron JN (1986) Principles of physiological measurement. Academic Press, London

Cech JJ (1990) Respirometry. In: Schreck CB, Moyle PB (eds) Bethesda, MD, p 335-362

Fisk D, Powell MD, Nowak BF (2002) The effect of amoebic gill disease and hypoxia on survival and metabolic rate of Atlantic salmon (Salmo salar). Bull Eur Assoc Fish Pathol 22:190-194

Hauck AK (1984) A mortality and associated tissue reactions of chinook salmon, Oncorhyhnchus tshawytscha (Walbaum) caused by the microsproidian Loma sp. J Fish Dis 7: 217-229

Kent ML, Elliot DG, Groff JM, Hedrick RP (1989) Loma on early drafts of this manuscript, and to the anonymous

Becker JA, Speare DJ, Daley J, Dick P (2002) Effects of monMethods for fish biology. American Fisheries Society, 
salmonae (Protozoa: Microspora) infections in seawater reared coho salmon Oncorhynchus kisutch. Aquaculture 80:211-222

Lee CG (2002) Swimming performance, metabolic rate and recovery of adult Pacific salmon (Oncorhynchus spp.) with consideration of temperature effects. MSc thesis, Simon Fraser Unviersity, Burnaby, BC

Lee CG, Devlin RH, Farrell AP (2003) Swimming performance, oxygen consumption and excess post-exercise oxygen consumption in adult transgenic and oceanranched coho salmon. J Fish Biol 62:753-766

Ramsay JM, Speare DJ, Becker JA, Daley J (2003) Loma salmonae-associated xenoma onset and clearance in rainbow trout, Oncorhynchus mykiss (Walbaum): comparisons of per os and cohabitation exposure using survival analysis. Aquac Res 34:1329-1335

Sanchez JG, Speare DJ, Markham RJF (2000) Normal and aberant tissue distribution of Loma salmonae (Microspora) within rainbow trout, Oncorhynchus mykiss (Walbaum),

Editorial responsibility: Wolfgang Körting,

Hannover, Germany following experimental infection at water temperatures within and outside of the boundaries of the xenomaexpression temperature boundaries. J Fish Dis 23:235-242

Sanchez JG, Speare DJ, Markham RJF (2001a) Altered tissue distribution of Loma salmonae: effects of natural and acquired resistance. J Fish Dis 24:33-40

Sanchez JG, Speare DJ, Markham RJF, Jones SRM (2001b) Isolation of a Loma salmonae variant: biological characteristics and host range. J Fish Biol 59:427-441

Speare DJ, Brackett J, Ferguson HW (1989) Sequential pathology of the gills of coho salmon with a combined diatom and microsproidian gill infection. Can Vet J 30: 571-575

Speare DJ, Daley J, Markham RJF, Sheppard J, Beaman HJ, Sanchez JG (1998) Loma salmonae-associated growth rate suppression in rainbow trout, Oncorhynchus mykiss (Walbaum), occurs during early onset xenoma dissolution as determined by in situ hybridisation and immunohistochemistry. J Fish Dis 21:345-354

Submitted: May 17, 2005; Accepted: August 25, 2005

Proofs received from author(s): November 21, 2005 